\title{
Effect of Cement Type and Micro-cracks on Chloride Penetration in Concrete
}

\section{Nicoletta Russo ${ }^{1}$, Matteo Gastaldi ${ }^{1}$, Luca Schiavi ${ }^{2}$, Alberto Strini $^{2}$, Riccardo Zanoni ${ }^{2}$ and Federica Lollini ${ }^{1}$}

\author{
${ }^{1}$ Politecnico di Milano, Department of Chemistry, Materials and Chemical Engineering \\ “Giulio Natta”, Piazza Leonardo da Vinci 32, 20133 Milano, Italy, nicoletta.russo@polimi.it \\ matteo.gastaldi@polimi.it federica.lollini@polimi.it \\ ${ }^{2}$ Consiglio Nazionale delle Ricerche, Istituto per le Tecnologie della Costruzione, \\ Viale Lombardia 49, 20098 San Giuliano Milanese, Italy, luca.schiavi@itc.cnr.it \\ alberto.strini@itc.cnr.it riccardo.zanoni@itc.cnr.it
}

\begin{abstract}
Chloride-induced corrosion of reinforcing steel rebar is one of the major durability issues affecting reinforced concrete structures (RC). Various models have been developed to assess the durability design with regard to corrosion prevention in chloride-bearing environments, which refer mainly to uncracked concrete. Cracks, however, are frequently present in real RC structures and accelerate corrosion initiation of steel reinforcement, resulting in a shortened service life. This paper presents preliminary results concerning chloride-penetration resistance of different types of uncracked and cracked concrete, made with Ordinary Portland (OPC), Portland-Limestone (PLC) and Pozzolanic cement $(P C)$ and a water/cement ratio of 0.45. Load-induced micro-cracks were obtained with a specifically developed technique. Cracked and uncracked concrete specimens were immersed in a sodium chloride solution for 32 and 90 days. The chloride penetration front was detected on split surfaces, perpendicular to the exposed surface, with a colorimetric technique to evaluate the combined effect of cracks and cement type on the chloride-penetration resistance of different concretes. Results showed that in uncracked conditions cement type strongly affected chloride penetration depth in concrete. A mathematical model was applied to evaluate chloride diffusion coefficient (D) from chloride penetration depth measurements and exposure time. The lowest value of $D$ was found for PC concrete, that can be attributed to a higher pore refinement in the cement paste, five times higher for OPC and nine times higher for PLC. In cracked conditions, an additional penetration of chlorides occurred in correspondence of crack, even for micro-cracks 10-50 $\mu \mathrm{m}$ wide and $8-30 \mathrm{~mm}$ deep, leading to a decrease in chloride penetration resistance. The model however did not provide for an estimation of $D$ in correspondence of the crack.
\end{abstract}

Keywords: Reinforced Concrete Durability, Cracked Concrete, Chloride Penetration Resistance.

\section{Introduction}

Reinforced Concrete (RC) is one of the most widely used construction materials for the realization of modern structures and architectures. The considerable efforts made in the recent past to understand the degradation processes affecting $\mathrm{RC}$ constructions led to the development of useful tools and design models aimed at preventing corrosion of steel reinforcement rebar, which is the main cause of premature failure of RC structures (Bertolini et al., 2004). These tools and models require several durability-related design parameters, among which the chloride penetration resistance of concrete is of particular relevance for the evaluation of the service life of a RC structure in chloride-contaminated environment. 
Several studies have been carried out to investigate the main influencing factors of chloride penetration resistance of concrete, such as, for instance, the cement type. However, these studies - as well as current durability design models - often refer to uncracked concrete, a condition that is rarely met in real RC structures. Cracks in the concrete cover represent a privileged path for chlorides and it is therefore of fundamental importance to evaluate the effects of cracks on chloride penetration resistance of concrete (ACI 201.2R-16, 2016).

In recent years, an ever increasing number of studies has been addressed to this topic ( $\mathrm{Gu}$ et al., 2015) and, as a general result, it seems that even micro-cracks (crack opening smaller than $100 \mu \mathrm{m}$ ) can locally affect chloride penetration in concrete (Yoon and Schlangen, 2014). In some tests the chloride penetration resistance is evaluated by means the so called colorimetric method. One of the advantages in applying this method to cracked concrete is that it provides a visual detection of chloride penetration in correspondence and in the vicinity of crack. In literature, this method has often been applied to concrete specimens with wide artificial cracks (notches) subject to accelerated exposure test (Audenaert et al., 2007, Marsavina et al., 2009, Li et al., 2016). Few studies, however, have been addressed to the application of colorimetric technique on cracked specimens subject to natural exposure conditions.

In this study, preliminary results are presented within a wider research project concerning the effects of cracks on RC durability. The chloride penetration resistance of three different types of concrete, obtained with water/cement ratio of 0.45 and different cements, was evaluated in uncracked and load-induced micro-cracked configurations. After the immersion

of the concrete specimens in NaCl solution for 32 and 90 days, the chloride penetration was
evaluated via colorimetric technique, and was correlated with crack geometrical parameters.
2.1 Materials and Specimens

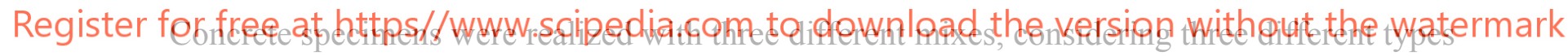
of cement. Details on concrete mixing proportions, and properties at fresh and hardened state are reported in Table 1.

Table 1. Concrete mixing proportions and properties.

\begin{tabular}{lccc}
\hline & OPC & PLC & PC \\
\hline Cement, $\mathrm{kg} / \mathrm{m}^{3}$ & 422 & 422 & 422 \\
\hline Water, $\mathrm{kg} / \mathrm{m}^{3}$ & 190 & 190 & 190 \\
\hline Aggregate, $\mathrm{kg} / \mathrm{m}^{3}$ & 1731 & 1731 & 1731 \\
\hline $\mathrm{w} / \mathrm{c}$ & 0.45 & 0.45 & 0.45 \\
\hline Superplasticizer, $\mathrm{mL}$ & 15.5 & 10 & 12 \\
\hline Slump, $\mathrm{mm}$ & 130 & 170 & 165 \\
\hline Density, $\mathrm{kg} / \mathrm{m}^{3}$ & 2496 & 2526 & 2477 \\
\hline $\mathrm{f}_{\mathrm{c}, \text { cube, } 7 \text { days }}, \mathrm{MPa}$ & 54.0 & 56.9 & 54.6 \\
\hline $\mathrm{f}_{\mathrm{c}, \text { cube, } 28 \text { days },}, \mathrm{MPa}$ & 76.9 & 60.8 & 67.4 \\
\hline $\mathrm{f}_{\mathrm{c}, \text { cube, } 120 \text { days },} \mathrm{MPa}$ & 86.9 & 76.8 & 81.4 \\
\hline
\end{tabular}


It was considered an Ordinary Portland Cement (OPC) type CEM I 42,5R as reference, a Portland-Limestone Cement (PLC) type CEM II/A-LL 42,5R, which is one of the most widely used in Italy, and a cement with pozzolanic additions, Pozzolanic Cement (PC) type CEM IV/A(V) 42,5R-SR. The concrete mixes were obtained with $422 \mathrm{~kg} / \mathrm{m}^{3}$ of cement and $190 \mathrm{~kg} / \mathrm{m}^{3}$ of water (w/c ratio equal to 0.45 ), and $1731 \mathrm{~kg} / \mathrm{m}^{3}$ of limestone aggregates with maximum diameter of $9 \mathrm{~mm}$. To improve workability at fresh state, an acrylic-based superplasticizer was added to each mix. For each concrete type, six cubic specimens $100 \mathrm{~mm}$ side were cast for compressive strength, which was executed after 7, 28 and 120 days of moist curing on two specimens per time. For chloride penetration resistance six prismatic specimens of dimensions $120 \times 90 \times 50 \mathrm{~mm}$ were manufactured for each concrete type. To promote the formation of the crack during the cracking procedure, four prismatic specimens were provided with a central $\mathrm{V}$-shaped notch, about $5 \mathrm{~mm}$ deep, along the longitudinal direction on the casting surface. After casting, all concrete specimens were covered with a plastic film. The subsequent day were demoulded and placed in the curing chamber (four of them after the cracking procedure), where they were kept at $20^{\circ} \mathrm{C}$ and $\mathrm{RH}>90 \%$ for 28 days. Table 1 shows the average concrete properties at hardened state. An increase of compressive strength in time was observed, with compressive strengths of 77,61 and $68 \mathrm{MPa}$ reached respectively by OPC, PLC and PC concretes after 28 days of moist curing.

\subsection{Cracking Procedure}

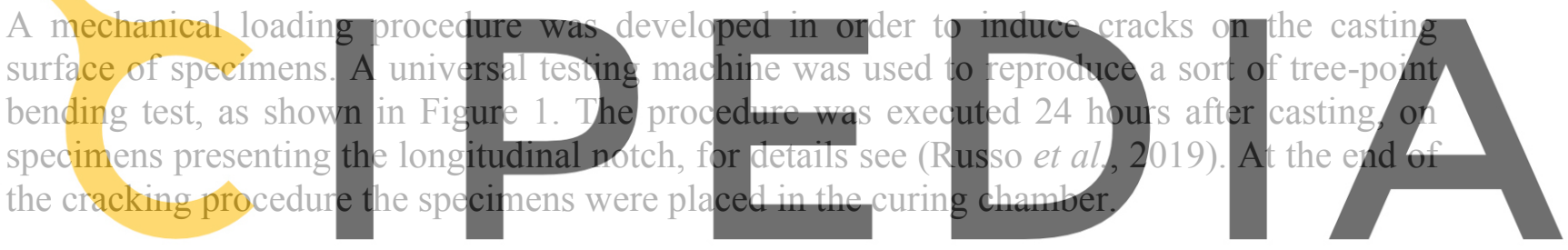

Register for free at https//www.scipedia.com to download the version without the watermark

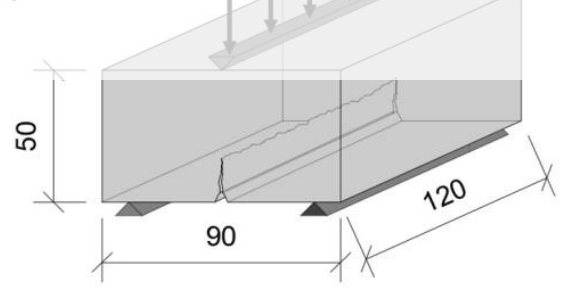

Figure 1. Specimen geometry (dimensions in $\mathrm{mm}$ ) and cracking procedure.

\subsection{Chloride Penetration Resistance}

Uncracked and cracked concrete specimens were exposed to chlorides by immersion (EN 12390-11:2005). After 28 days of curing the specimens were vacuum saturated with demineralized water. At the end of the saturation procedure they were left immersed in water and within 24 hours removed from water in order to seal with epoxy resin all the surfaces, except for the casting surface. After 24 hours the specimens were immersed in a saturated solution of calcium hydroxide for 18 hours. Finally, all the specimens were immersed in a 3\% 
by mass sodium chloride solution, for 32 and 90 days (concrete will be henceforth identified with a code indicating the cement type and the days of exposure, e.g. OPC-90 for specimens obtained with Ordinary Portland Cement and exposed to chlorides for 90 days). At the end of the exposure time, the specimens were split with a hydraulic press in one point along the longitudinal direction, and therefore perpendicular to the crack plane for cracked specimens.

On the freshly split surfaces a silver nitrate solution $(0.1 \mathrm{M})$ was sprayed, in order to evaluate the chloride penetration profile. The chloride penetration depth was measured in seven different positions, i.e. in the central point and at a distance of $10 \mathrm{~mm}, 20 \mathrm{~mm}$ and 30 $\mathrm{mm}$ on each side. For cracked specimens, the central measure was done starting from the tip of the notch, in order to exclude its influence on the penetration profile. A further measure was also done for cracked specimens, corresponding to the maximum penetration depth starting from the tip of the notch. For each concrete type, two cracked specimens were provided for each exposure time, while the same two uncracked specimens were used for both the exposure times. The fracture surfaces of the uncracked specimens analyzed after 32 days of exposure were sealed with epoxy resin, and the day after were exposed again to chlorides, in order to be analyzed also after 90 days of exposure. After chloride penetration measurements the split surface was impregnated with a colored superfluid two-component epoxy resin. The following day, a thin concrete slice, parallel to the split surface where chloride penetration depth was evaluated, was cut with a water cooled cutting saw. The concrete thin slice was then polished and observed at the stereoscopic microscope in order to

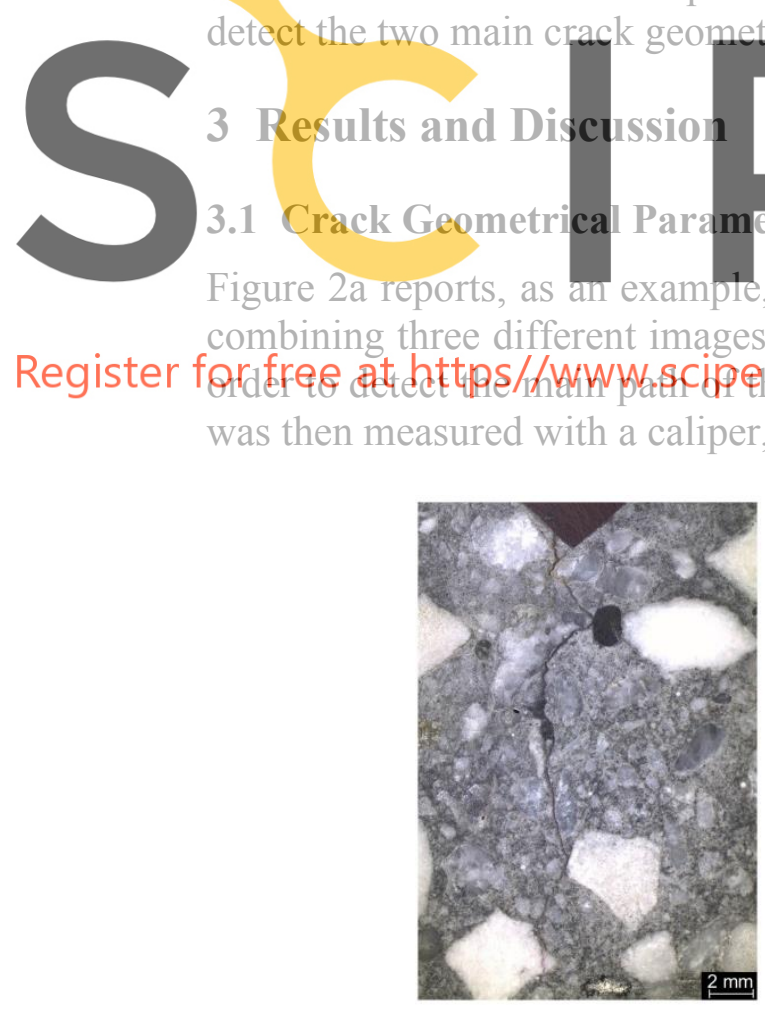

(a)

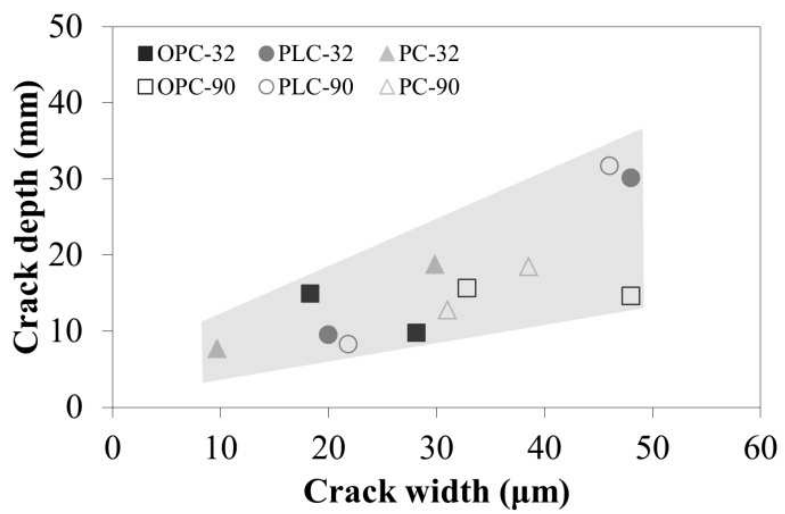

(b)

Figure 2. (a) Microscopic image of cracked PC-90 specimen; (b) Crack width as a function of crack depth. 
The parameter crack width is intended as the crack opening at the exposed surface, in correspondence of the tip of the notch. Five measurements were done at $50 \times$ of magnification, in a range of about one millimeter from notch tip, and then averaged. Figure $2 b$ reports the results obtained for the two replicated samples of the three concrete types after the two exposure times. Crack widths resulted to be included in the range $10-50 \mu \mathrm{m}$, while crack depth included in the range $8-30 \mathrm{~mm}$. Despite data were characterized by a quite high dispersion, increasing crack width an increase also in crack depth was observed, which was independent from the cement type and the exposure time.

\subsection{Chloride Penetration Resistance}

A colorimetric technique was used to evaluate the chloride penetration profiles on the split surfaces of different cracked and uncracked concretes. Figure $3 \mathrm{a}$ and $3 \mathrm{c}$ show, as an example, the chloride penetration profile in PLC uncracked and cracked specimens respectively, after 32 days of exposure. The penetration depths in different points after 32 days of exposure for the three cement types are reported in Figure $3 \mathrm{~b}$ for sound and $3 \mathrm{~d}$ for cracked configuration.
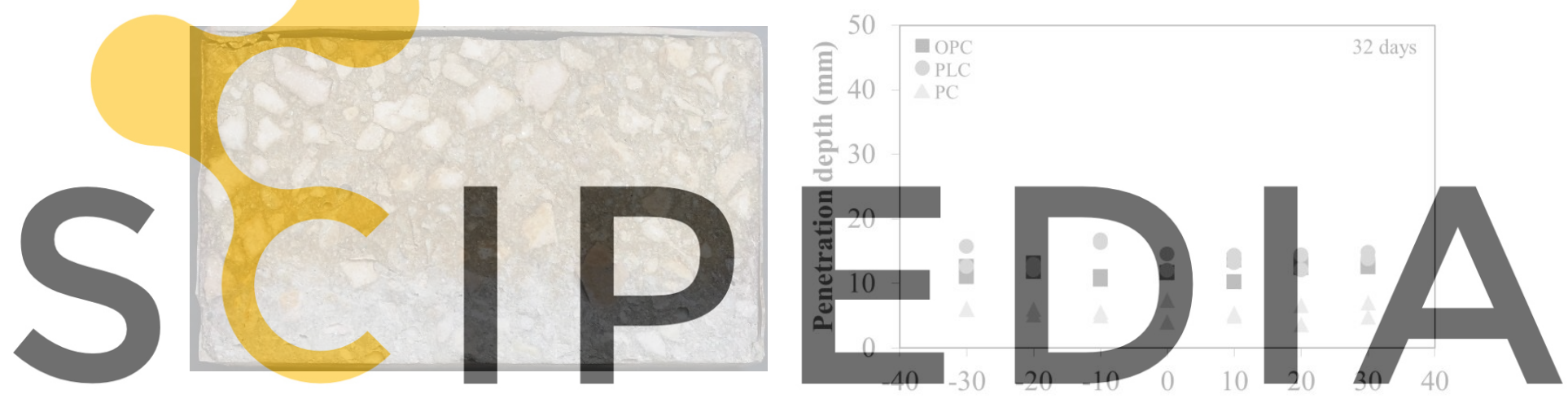

Distance from central axis $(\mathrm{mm})$

\section{Register for free at https//Wwiw.scipedia.com to download the ver\$on without the watermark}

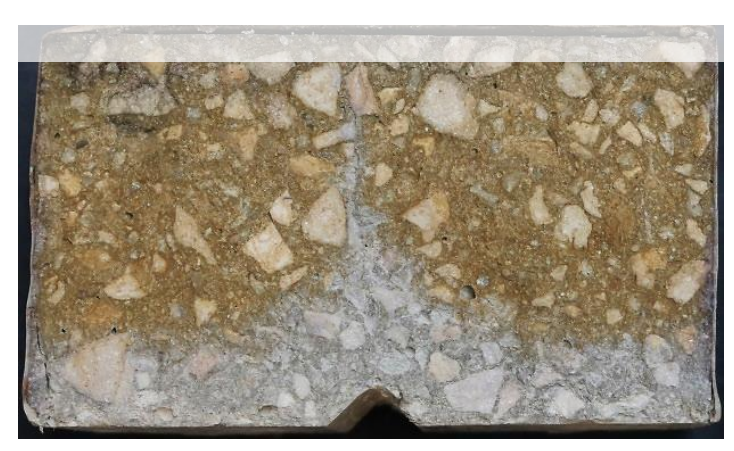

(c)

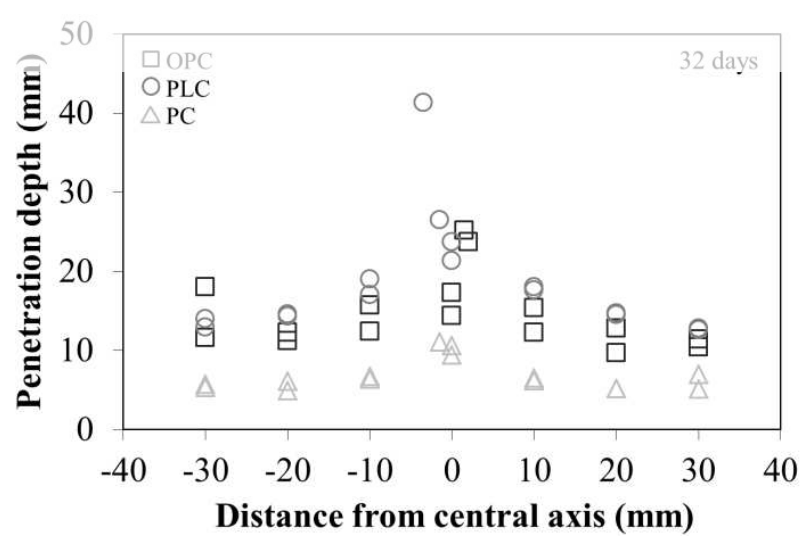

(d)

Figure 3. Chloride penetration in PLC-32 (a) uncracked and (c) cracked specimen; Chloride penetration depth measured in different points at different distances from the central axis of the specimen for different concrete types in (b) uncracked and (d) cracked specimens after 32 days of exposure. 


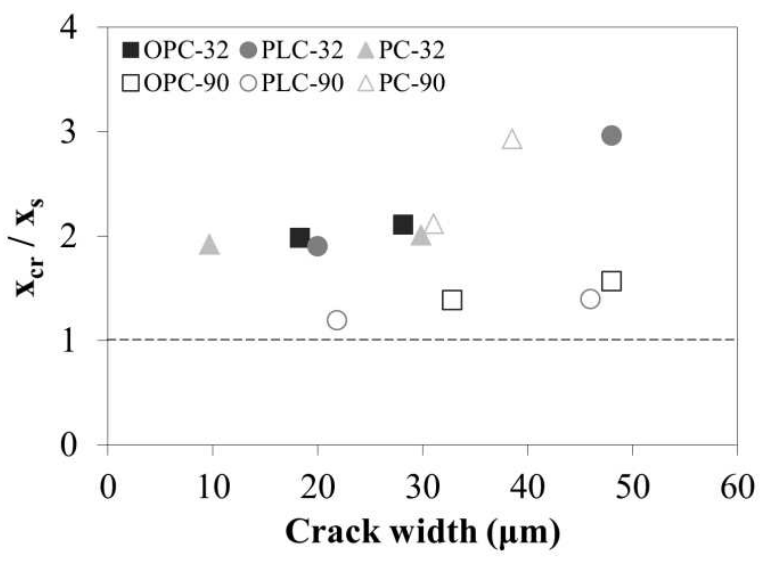

(a)

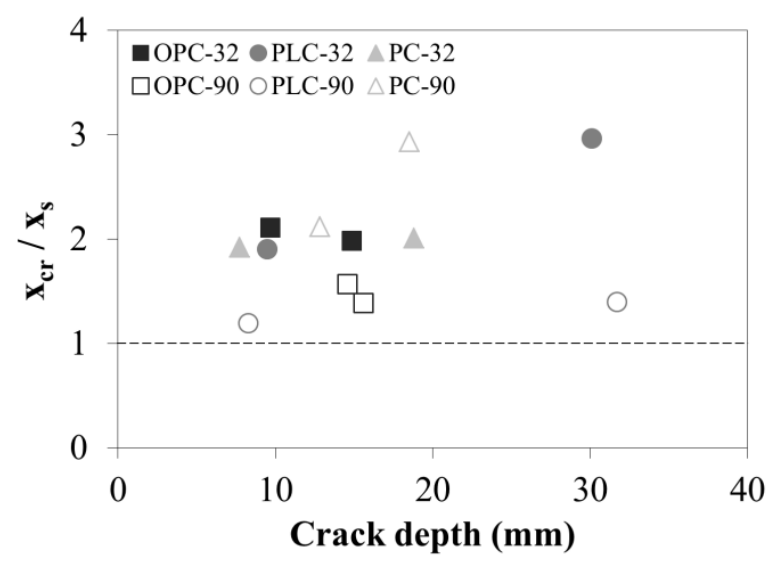

(b)

Figure 4. Local increase of chloride penetration depth in correspondence of the crack with respect to sound conditions, as a function of (a) crack width and (b) crack depth.

In Figure $3 \mathrm{~b}$ it can be observed that, in sound conditions and for each type of concrete, the penetration depth was almost constant along the specimen and comparable between the two replicate specimens. As expected the lowest chloride penetration profiles were referred to the PC cement type, showing a chloride penetration depth of about $5 \mathrm{~mm}$ after 32 days of

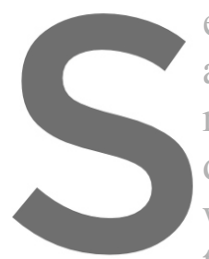
exposure. This can be atr a higher chloride penet results of compressive was detected on cracked the central axis, where
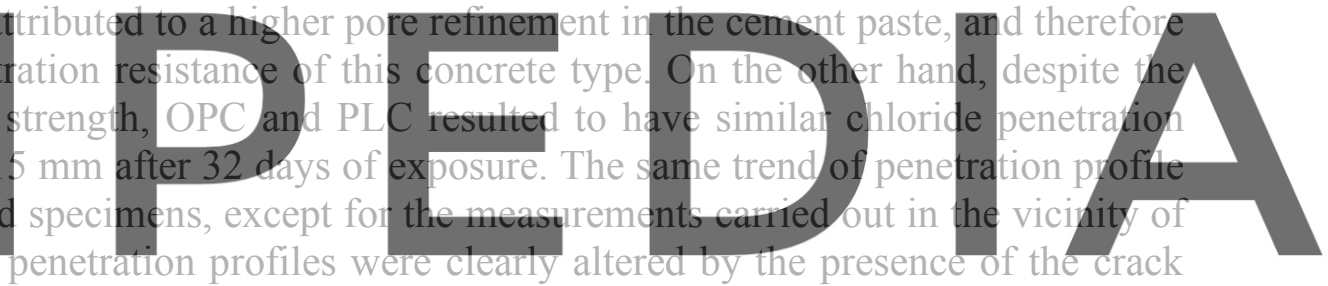

(in this point the measurements were done starting from the tip of the notch)

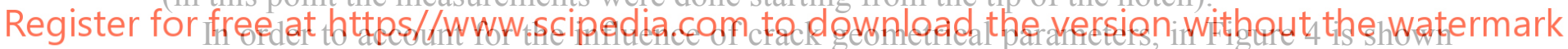

the local increase in chloride penetration depth in correspondence of the crack with respect to

sound conditions $\left(\mathrm{x}_{\mathrm{cr}} / \mathrm{x}_{\mathrm{s}}\right)$ as a function of crack width and crack depth for both the exposure time. $x_{\mathrm{cr}} / \mathrm{x}_{\mathrm{S}}$ represents the ratio between the chloride penetration depth in the crack and the average penetration depth in sound specimens. It can be observed that chloride penetration in the crack resulted always higher with respect to uncracked conditions, until a maximum of 3 times higher. The local increase of penetration depth in the crack after 32 days of exposure resulted always doubled for crack widths included in the range 10-30 $\mu \mathrm{m}$ and crack depth about $10-20 \mathrm{~mm}$, independently from the concrete type, indicating that micro-cracks could lead to a significant increase of the chloride penetration. After 90 days of exposure, for PC concrete the local increment in correspondence of crack was still similar, while for OPC and PLC a lower local increment was detected, included in the range 1.2-1.5, although crack parameters were comparable to those at 32 days of exposure. This effect will be further investigated to understand if it is due to some self-healing effects, or simply to data scattering.

From the measurements of penetration depths, an attempt was made in order to evaluate chloride penetration resistance of the different concretes in terms of chloride diffusion coefficient. The diffusion coefficient was calculated considering a linear correlation between 
the chloride penetration depth and the square root of time, according to the relationship proposed by Collepardi et al., 1970:

$$
x=4 \sqrt{D t}
$$

where $x$ is the chloride penetration depth, $t$ is time and $D$ is the chloride diffusion coefficient of concrete.

Figure 5 shows the relationship between the chloride penetration depths for different concretes and the square root of time. It seems that for all cement types in uncracked conditions there is a general decrease in the chloride penetration rate over time (i.e. ageing effect), which has already been detected (Collepardi and Biagini, 1989), although for longer exposure times with respect to those considered in this study. Anyway, a single linear interpolation was done for each type of concrete, and the values of the diffusion coefficient are reported in the chart legend. The highest chloride penetration resistance was detected for the $\mathrm{PC}$ concrete, whose chloride diffusion coefficient resulted equal to $0.34 \times 10^{-12} \mathrm{~m}^{2} / \mathrm{s}$, while $D$ was more than 5 times higher for OPC concrete $\left(1.79 \times 10^{-12} \mathrm{~m}^{2} / \mathrm{s}\right)$ and nine times higher for PLC $\left(3.06 \times 10^{-12} \mathrm{~m}^{2} / \mathrm{s}\right)$, consistent with literature data (Collepardi and Biagini, 1989). The determination of the diffusion coefficient from the correlation (1) in the case of cracked configurations resulted to have some limitations, not only because of the ageing effect but also because of crack geometrical parameters, which were different in correspondence of different measurement surfaces. For PC the linear correlation was still able to fit results, and the value of the diffusion coefficient in the crack resulted to be equal to $1.82 \times 10^{-12} \mathrm{~m}^{2} / \mathrm{s}$, more than five times higher than the value measured
and PLC cement types, a linear corrclation,
detected. This is a direct consecuenee of the
showed lower local increase in chloride pen pers at 90 days of exposure.
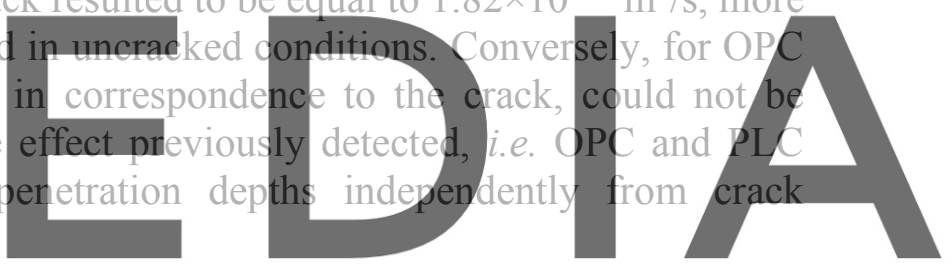

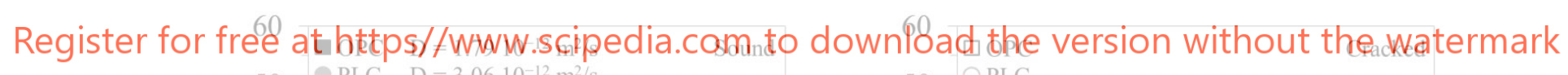

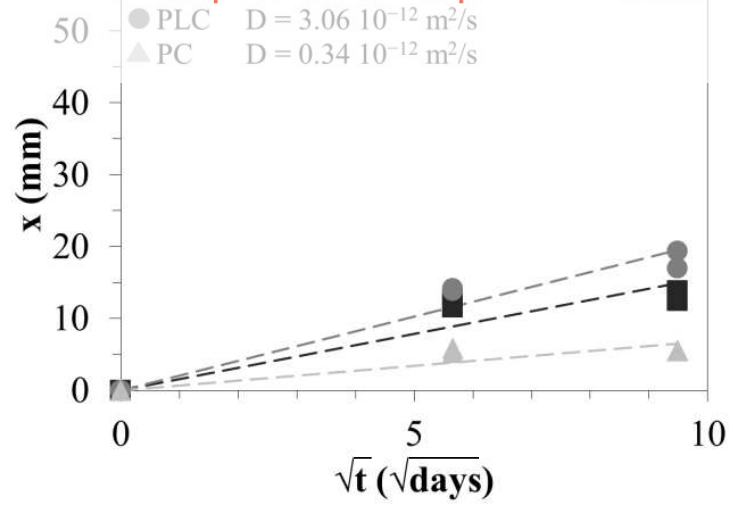

(a)

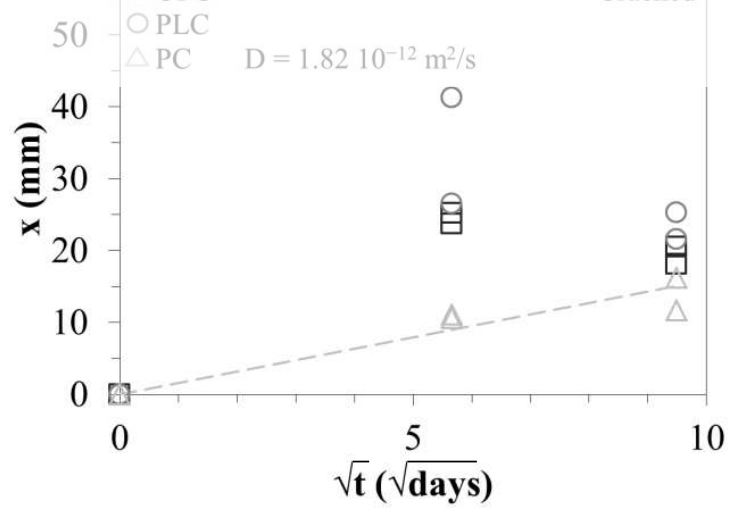

(b)

Figure 5. Chloride penetration depths as a function of the square root of time for the different concretes in (a) sound and (b) cracked conditions. 


\section{Conclusions}

Chloride penetration in concretes made with Ordinary Portland (OPC), Portland-Limestone (PLC) and Pozzolanic (PC) cement was investigated through a colorimetric technique in uncracked and cracked configurations. Cracked specimens were obtained with a sort of threepoint bending procedure able to generate $\mathrm{V}$-shaped micro-cracks, with crack opening included in the range 10-50 $\mu \mathrm{m}$ and crack depth included in the range $8-30 \mathrm{~mm}$. In uncracked configuration, PC was the concrete type showing lowest chloride penetration depths, due to a higher pore refinement. In cracked configuration the chloride additional penetration in the crack $\left(\mathrm{x}_{\mathrm{cr}} / \mathrm{x}_{\mathrm{s}}\right)$ was evaluated as a function of two main geometrical parameters, crack width and crack depth. Independently from the concrete type, $\mathrm{x}_{\mathrm{cr}} / \mathrm{x}_{\mathrm{s}}$ was always included in the range 1.2-3. Chloride penetration resistance of different uncracked and cracked concretes was investigated also in terms of chloride diffusion coefficient $(D)$. In uncracked conditions $D$ resulted to be equal to $1.79 \times 10^{-12} \mathrm{~m}^{2} / \mathrm{s}$ for OPC, $3.06 \times 10^{-12} \mathrm{~m}^{2} / \mathrm{s}$ for PLC and $0.34 \times 10^{-12} \mathrm{~m}^{2} / \mathrm{s}$ for $\mathrm{PC}$ concrete. The application of the same mathematical model to cracked concrete resulted limited by the fact that crack geometrical parameters were not considered.

\section{ORCID}

Nicoletta Russo: https://orcid.org/0000-0003-3919-0094 Matteo Gastaldi: https://orcid.org/0000-0002-1392-2691

Luca Schiavi: http://orcid.org/0000-0001-5574-1584

Alberto Strini: http://orcid.org/0000,0001-9585-2748

Federica Lollini: http://ordic.

References

ACI Committee 201, (2016). ACI 201.2R-16 Guide to Durable Concrete.

Audenaert, K., De Schutter,
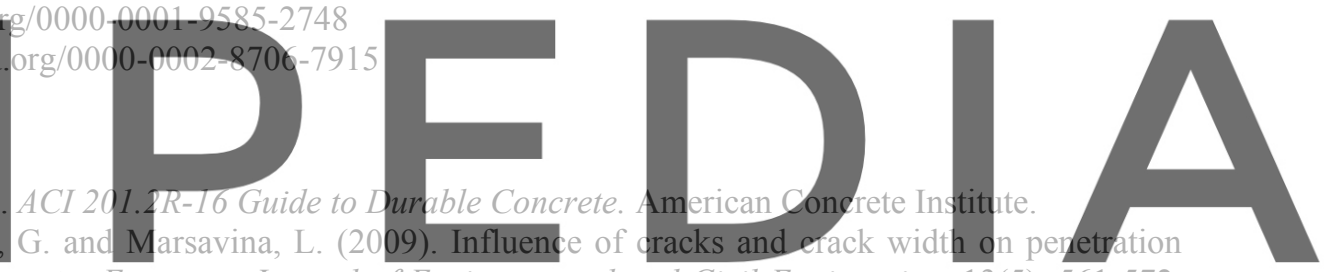
doi: 10.3166/EJECE.13. 561-572

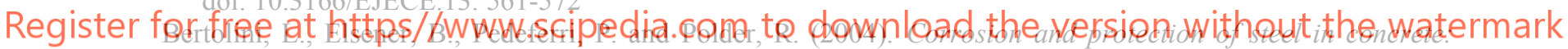
prevention, diagnosis, repair. Wiley.

Collepardi, M. and Biagini, S. (1989). Effect of water/cement ratio, pozzolanic addition and curing time on chloride penetration into concrete. In Proceedings of the ERMCO '89, Stavanger, Norway, 606-615.

Collepardi, M., Marcialis, A. and Turriziani, R. (1970). La cinetica di penetrazione degli ioni cloruro nel calcestruzzo. Il Cemento, 67, 157-164.

$\mathrm{Gu}, \mathrm{C}$., Ye, G. and Sun, W. (2015). A review of the chloride transport properties of cracked concrete: experiments and simulations. Journal of Zhejiang University-SCIENCE A, 16, 81-92. doi: 10.1631/jzus.A1400247

Li Y., Chen X., Jin L. and Zhang R. (2016). Experimental and numerical study on chloride transmission in cracked concrete. Construction and Building Materials, 127, 425-435. doi: 10.1016/j.conbuildmat.2016.10.044

Marsavina, L., Audenaert, K., De Schutter, G., et al., (2009). Experimental and numerical determination of the chloride penetration in cracked concrete. Construction and Building Materials, 23(1), 264-274. doi: 10.1016/j.conbuildmat.2007.12.015

Russo, N., Gastaldi, M., Marras, P., Schiavi, L., Strini, A. and Lollini, F. (2019). A preliminary study on the effects of cracks on chloride penetration in different concretes. In Proceedings of the $V$ Workshop on The New Boundaries of Structural Concrete, Milan, Italy, 315-324.

Yoon I.S. and Schlangen E. (2014). Experimental examination on chloride penetration through micro-crack in concrete. KSCE Journal of Civil Engineering, 18, 188-198. doi: 10.1007/s12205-014-0196-9 